\title{
Determination of Internal Waves Off the Coast of Morocco According to Earth Remote Sensing Data
}

\author{
Tatyana Tatarnikova ${ }^{1,2}$, Irma Martyn ${ }^{1,3}$, Sergey Stepanov ${ }^{1,4}$, Yaroslav Petrov ${ }^{1,5}$, \\ Artem Sidorenko ${ }^{1,6}$ \\ ${ }^{1}$ Department of applied computer science, Russian State Hydrometeorological University, 79 \\ Voronezhskaya Street, St. Petersburg 192007, Russian Federation \\ 2 tm-tatarneyandex.ru \\ 3 irma martyn@mail.ru \\ 4 stepanov.sergey.yegmail.com \\ 5 yaroslav.petrov025@gmail.com \\ 6 sidorenko.reflgmail.com
}

\begin{abstract}
This paper presents the results of a study of the internal wave isolation of the Northern coast of Morocco using synthetic aperture radar (SAR) images. A filter is applied to the remote sensing data to reduce the image grain, after which the direction of propagation of the wave is determined and its length is calculated. In most cases, internal waves appear on satellite images as quasi-periodic linear structures whose brightness is lower or higher than the background, which is well registered in the visible range and by synthetic aperture radar. When analyzing images off the coast of Morocco, internal waves were detected, the wave packet propagates in the direction from West to East. When comparing the obtained images with the bottom relief map, it can be assumed that the generation of internal waves is caused by the roughness of the bottom near the Northern coast of Morocco. The maximum wave length in the wave packet is almost 0.7 $\mathrm{km}$, consists of at least 5 solitons, the prints of these solitons in the sea roughness area are visible in the images mainly in the Central part of a wave packet, the distance between a wave packet solitons is different. The wavelength decreases when moving to the back of a wave packet, which can be traced by changing the contrast on the site. As a result, internal waves were detected off the Northern coast of Morocco in rads images with a synthesized aperture, and the main characteristics of these waves were determined.
\end{abstract}

Keywords: Internal Waves, Remote Sensing of the Earth, Synthetic Aperture Radars.

Copyright (C) 2020 for this paper by its authors. Use permitted under Creative Commons License Attribution 4.0 International (CC BY 4.0). 


\section{Introduction}

Internal waves are a fairly common phenomenon found in stably stratified density waters. Internal waves are translational vibrations of a surface of constant density in a stratified fluid. Morocco is located in the subtropical zone [7], where due to the large amount of solar radiation and heating of the upper layers of the ocean, a stable thermocline is formed along which internal waves propagate $[1,6]$.

Internal waves arise as possible vibrations in a stratified fluid. The returning force for internal waves is the Archimedes force, which is determined by the vertical stratification of density, and for surface waves, the returning force is determined by the density gradient at the water-air interface [2, 3].

Density gradients in the ocean are quite small, therefore, to move particles vertically does not require large expenditures of energy and the amplitudes of internal waves can increase to large sizes (can reach tens of meters, but at the same time a slight increase in the level surface of the order of several centimeters) $[4,13]$. The cellular flows that accompany these oscillations are of the order of the phase velocities of the internal waves. These flows are created at the surface in the areas of convergence and divergence, in which short gravitational and capillary waves are transformed, which are an indicator of internal waves. Using these indicator waves, you can determine the presence of internal waves in remote sensing images [5].

\section{Materials and research methods}

Internal waves can most often be found at the borders of the continental slope, since these waves are excited by the tides, but can also be generated by the flow around the bottom inhomogeneities, by anemobaric forces, surges, and other reasons [11]. In the ocean, high-frequency and low-frequency internal waves are distinguished. A characteristic feature of the propagation of internal waves is their propagation by groups (wave packet), which have a complex structure. Each wave packet includes up to several tens of waves. Internal waves create a flow field on the surface, divergent and convergent components of which simulate gravitational-capillary waves and create a picture on the water surface in the form of quasi-parallel alternating light (rough surface rips) and dark (smoothed surface - slicks) bands that are visible on satellite image.

Of the means of remote sensing [14], space-based side-scan radars with a real antenna and synthetic aperture radars are considered the most effective for detecting internal waves. Thanks to the radar survey [9], the spatial characteristics of the internal waves and the mechanisms of their generation have become the most studied.

To detect and study the characteristics of internal waves [10] off the northern coast of Morocco, we used images of a radar with a synthesized aperture of the ERS-2 satellite. Images along with metadata can be obtained by users and can be selected according to any criteria (time range, geographic coordinates, etc.) After studying the images, a snapshot of the area where the internal waves were highlighted was selected (see Fig. 1). The resulting image was processed using the Bilko software package, where a filter was first applied to reduce the graininess of the image. After that, a detailed analysis 
[12] of the image became possible, and histograms were constructed from several sections of a wave packet. According to the diagram using the formula (1) wavelengths and height of the waves were calculated:

$$
\lambda=\sqrt{(d x \cdot p w)^{2}+(d y \cdot p w)^{2}},
$$

where $p w=75, d x=\left(x_{2}-x_{1}\right)$ - distance along the $\mathrm{x}$-axis, $d y=\left(y_{2}-y_{1}\right)$ - distance along the $y$-axis.

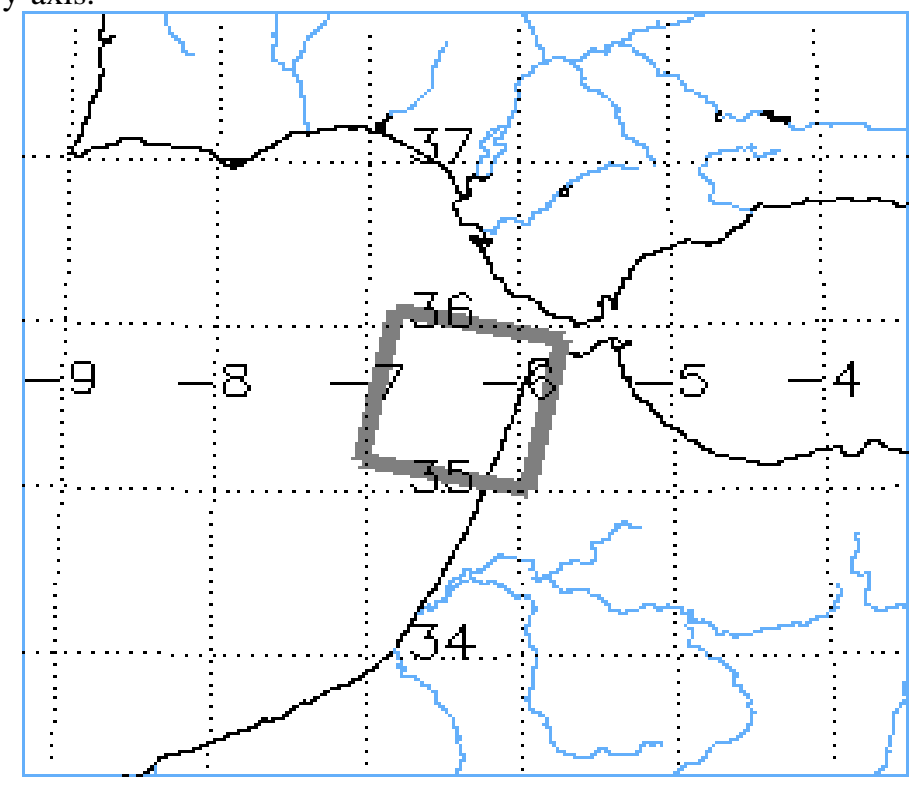

Fig. 1. Study area

\section{Research results and discussion}

A wave packet corresponding to internal waves in the area was found in the image. The place of generation of the presented internal waves is indicated in the image (see Fig. 2), according to the topographic map of the ocean floor (see Fig. 3), it is noted that the formation of internal waves in this region occurs due to uneven topography of the seabed, which is the reason for the generation of internal waves in coast of Morocco. The waves propagate from west to east, which can be judged by a wave packet [15], where in the rear there are smaller waves. 


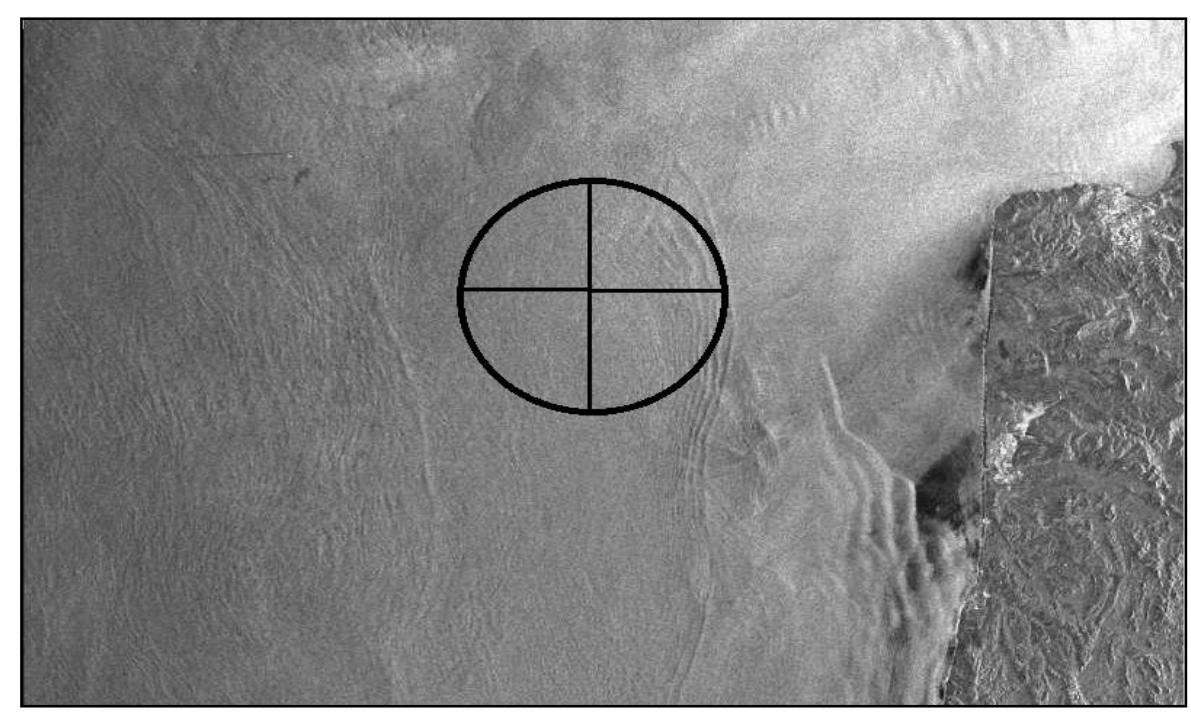

Fig. 2. Place of generation of internal waves

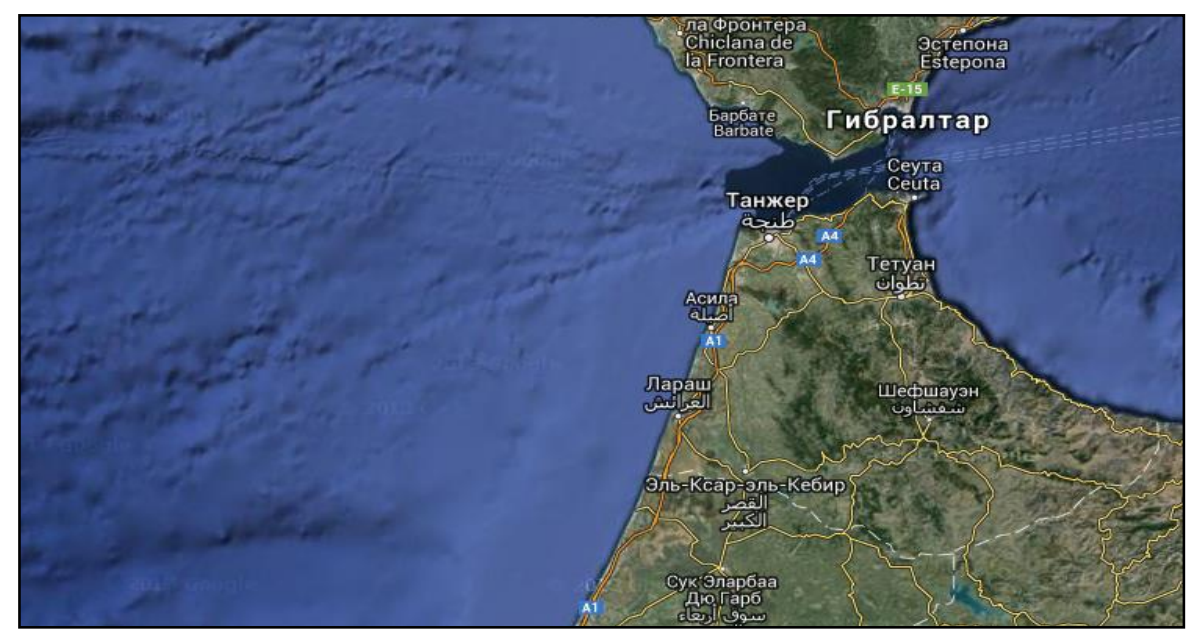

Fig. 3. Map of the bottom topography off the northern coast of Morocco

The calculation of wavelengths was carried out in three sections of the wave packet (see Fig. 4-7). Across all sections, the wavelength reaches almost $0.7 \mathrm{~km}$. The crest of the leading wave of the packet of internal waves reaches almost $170 \mathrm{~km}$, consists of at least 5 solitons, which are most marked in the central part of a wave packet, the distance between a wave packet solitons is different. The wavelength when moving to the rear of a wave packet decreases, which can be traced to the change in contrast in the section. 
Determination of Internal Waves Off the Coast of Morocco According to Earth... 5

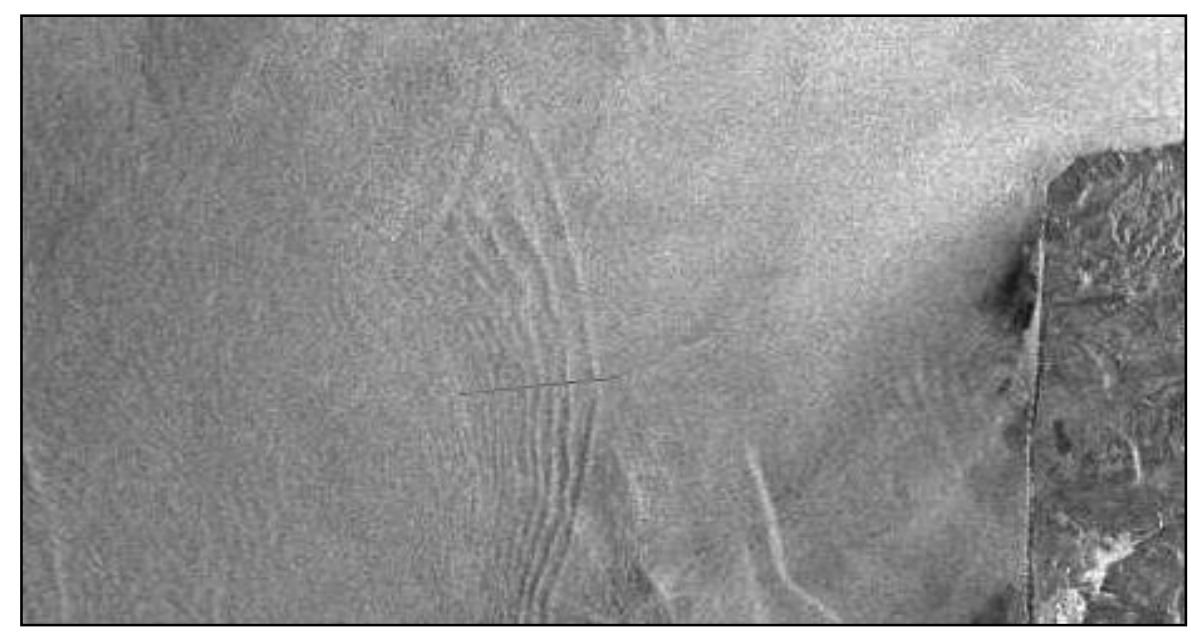

Fig. 4. PCA Cross-section satellite image

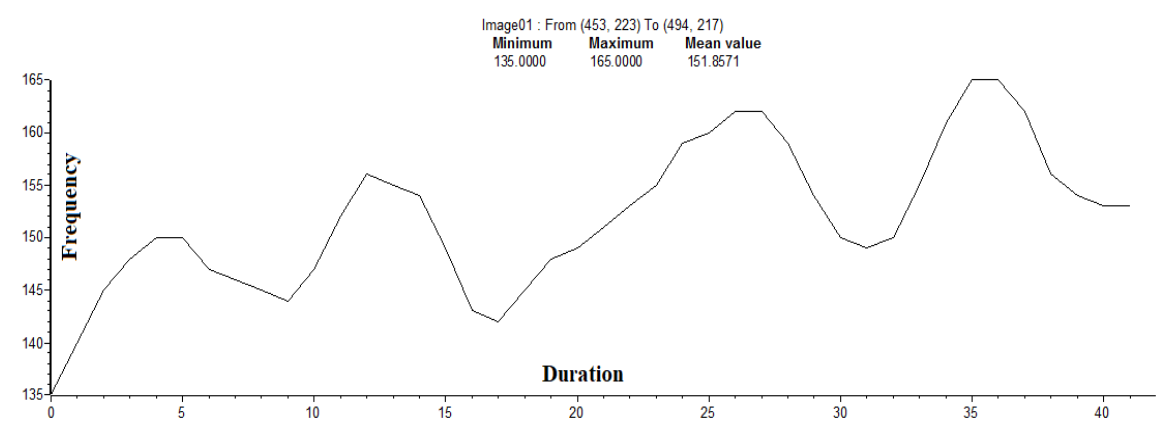

Fig. 5. Section of a wave packet at $d x=42, d y=-7$

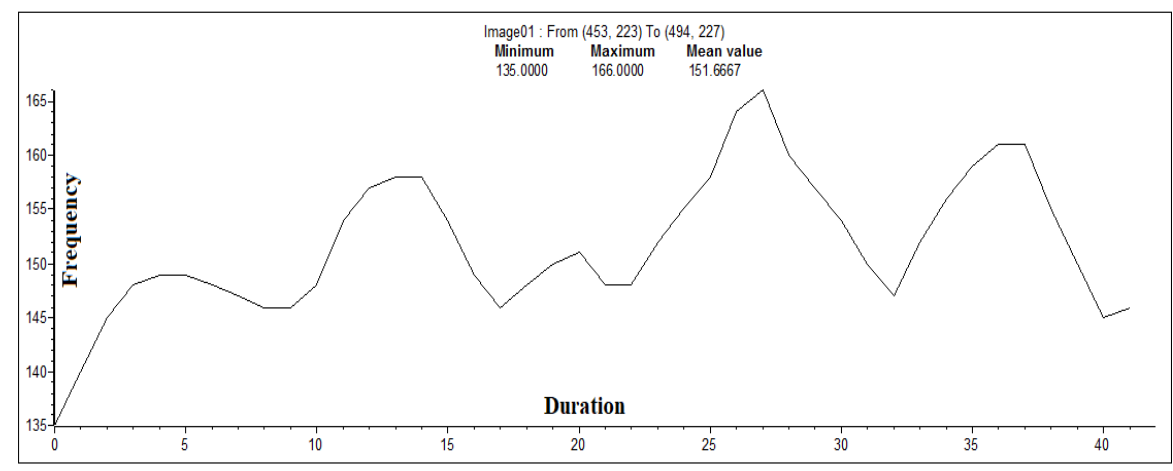

Fig. 6. Section of a wave packet at $d x=42, d y=5$ 


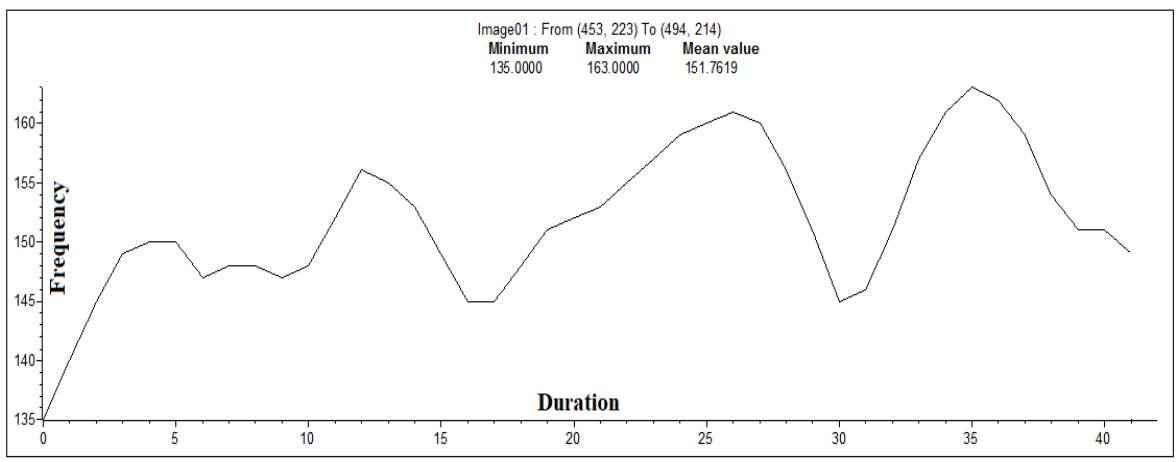

Fig. 7. Section of a wave packet at $d x=42, d y=-10$

A combined image graph with and without a filter (see Fig. 8) showed that the smoothed curve best describes the ongoing process. Using a filter [8] allows you to best identify the highs and lows in the diagram, identify individual waves.

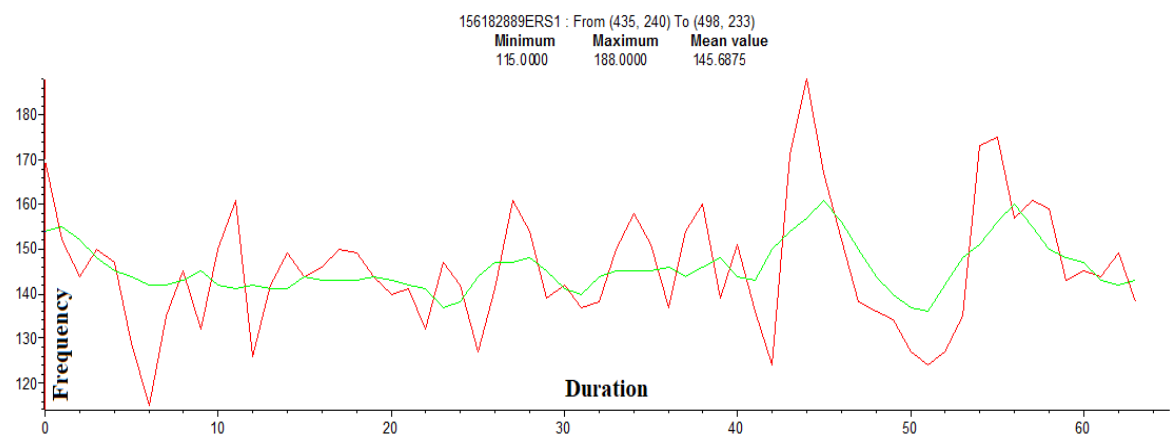

Fig. 8. Combined section graph using a filter (green line) without applying a filter (red line)

\section{Conclusion}

In the waters off the northern coast of Morocco, manifestations of internal waves on the ocean surface were detected by radars with a synthesized aperture in areas of uneven bottom topography. The observation was carried out on a detected packet of waves, the number of solitons is at least 5. The length of the leading wave crest reaches almost 170 $\mathrm{km}$. The propagation of a wave packet occurs mainly in a direction from west to east.

\section{References}

1. Bowden K. Physical Oceanography of coastal waters/ K. Bowden. - Moscow: Mir, 1988. $324 \mathrm{p}$.

2. V.N.Kiselev, A.D.Kuznetsov. Sounding methods of the environment (of the atmosphere)/ A textbook. St.Petersburg Publishers, 2004. - 429pp. 
3. Lowengart R. A. Remote sensing. Models and methods of image processing. Moscow: Technosphere, 2013. - $592 \mathrm{pp}$.

4. Sharkov E. A. Radioteplovoe remote sensing of the Earth: physical bases: in 2 vol. / Eugene Sharkov. - Vol. 1. - M.: IKI RAS, 2014. - 544c.

5. Dubinina V. A., Mitnik L. M., Katin I. O. Features of water circulation in the Peter the Great Bay based on satellite multisensory data/ V. A. Dubinina, L. M. Mitnik, I. O. Katin / / Current state and trends in the natural environment of the Peter the Great Bay of the sea of Japan / editor-in-chief V. A. Akulichev. - Moscow: GEOS, 2008. - Pp. 82-96.

6. Monin A. S., Ozmidov R. V. Oceanic turbulence: monograph. - L.: Hydrometeoizdat. 1981. $-320 \mathrm{pp}$.

7. Doronin Yu. P. Oceanography of the shelf zone. Textbook. - SPb., ed.RGGMU, 2007. $128 \mathrm{p}$.

8. Navrotsky V. V., Izergin V. L., Pavlova E. P. Generation of internal waves near the shelf border / / DAN. - 2003. - Vol. 338, No. 2. - Pp. 249-253

9. Martyn I. A., Stepanov S. Yu., Sidorenko A. Yu. Classification of the underlying surface according to satellite observations / / Proceedings of the III international scientific and practical conference of young scientists, 2019, Pp, 189-192.

10. Klymak M., Moum J.N. Internal solitary waves of elevation advancing on a shoaling shelf // Geophys. Res. Lett. - 2003. - Vol.30, №20. - P.2045

11. Benjamin, T.B. 1966 Internal waves of finite amplitude and permanent form J. Fluid Mech. 25, 241.

12. Istomin E., Petrov Y., Stepanov S., Sidorenko A. and other. About technology of risk management in forestry. IOP Conference Series: Earth and Environmental Science. 316. 012011. 10.1088/1755-1315/316/1/012011.

13. Istomin E., Petrov Y., Stepanov S., Sidorenko A. and other. Model of optimum integration of diverse geodata for the benefit of management of forestry. IOP Conference Series: Earth and Environmental Science. 316. 012013. 10.1088/1755-1315/316/1/012013.

14. E. Istomin, A. Sidorenko, S. Stepanov, Y. Petrov, I. Martyn Application of Kalman-Bucy filter for vessel traffic control systems in the northern sea route 2020 IOP Conf. Ser.: Mater. Sci. Eng. 817012012 https://doi.org/10.1088/1757-899X/817/1/012012

15. E. Istomin, I. Martyn, Y. Petrov, S. Stepanov and A. Sidorenko Study of intra-day dynamics of currents in the area of the navigable strait of Baltiysk to adjust the movement of water transport 2020 IOP Conf. Ser.: Mater. Sci. Eng. 817012013 https://doi.org/10.1088/1757899X/817/1/012013 